\title{
Intracranial Migration Of Ventriculo-Peritoneal Shunt Catheter
}

\author{
C Pereira, E Santos
}

\begin{abstract}
Citation
C Pereira, E Santos. Intracranial Migration Of Ventriculo-Peritoneal Shunt Catheter. The Internet Journal of Neurosurgery. 2004 Volume 2 Number 1.
\end{abstract}

DOI: $\underline{10.5580 / 26 \mathrm{ac}}$

\section{Abstract}

Shunt migration into the cranium is a rare complication of surgical treatment for hydrocephalus. The authors report a case of shunt migration in a child and discuss common physiopathology and treatment.

\section{INTRODUCTION}

The migration of ventriculo-peritoneal shunt catheter is a rare complication of surgical treatment for hydrocephalus. The migration may be in either direction and is more frequent with hard and spring loaded shunt tubes ${ }_{1,2}$.

The authors report a case of intracranial dislocation of a ventriculo-peritoneal shunt catheter. The pathophysiological mechanism of the catheter migration is discussed.

\section{CASE REPORT}

A male child was born by breech delivery at the $30^{\text {th }}$ week of gestation. Four months later a macrocephalia and a tense fontanel developed.

Computed tomography showed an increase of ventricular volume. The child underwent a ventriculoperitoneal shunt (medium pressure). On the $9^{\text {th }}$ postoperative day, the child was discharged. Some days later, the child returned to João Alves Filho Hospital (Aracaju - Sergipe - Brazil), with signs and symptoms of increased intracranial pressure. Dehydration, macrocephalia, tense fontanel and tumor in right posterior parietal region were present.

Computed tomography showed an increase of ventricular volume, air in right temporal horn and shunt tube in the cranium. (Figure 1). The child underwent surgical removal of the tube and a new tube was implanted in contralateral side. On the $7^{\text {th }}$ postoperative day, the child discharged. Nowadays, the child had been treated with anticonvulsivant drugs and ambulatory follow - up.

\section{Figure 1}

Figure 1: Computed tomography showing intracranial shunt catheter

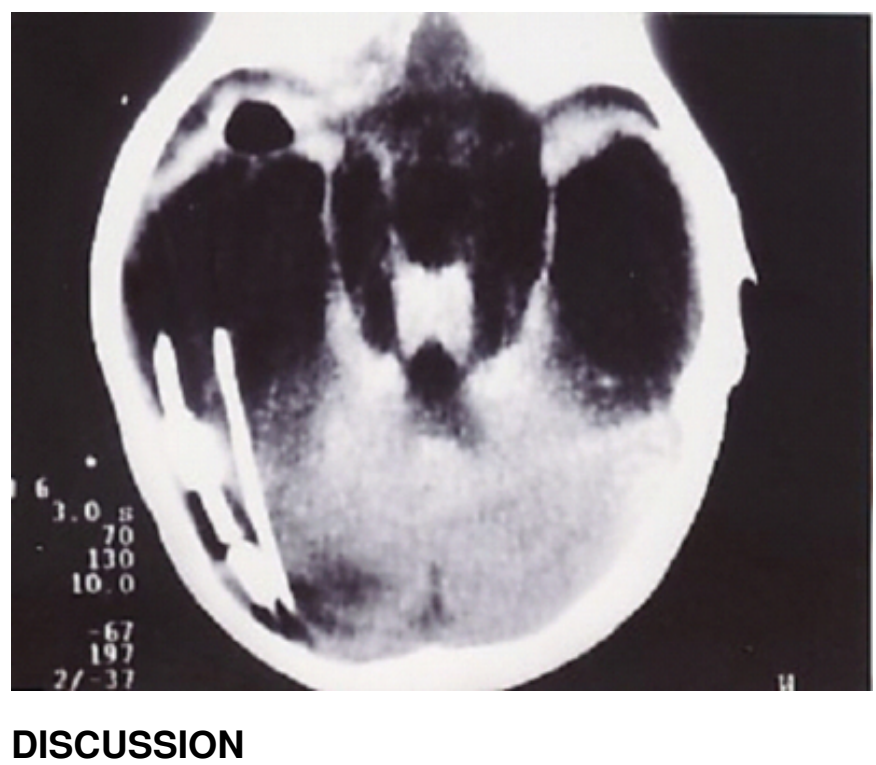

Shunt complications have been frequently reported in literature. The intracranial migration of ventriculo-peritoneal shunt is the most rare complication and constitutes $0,1 \%$ to $0,4 \%$ of all shunt procedures ${ }_{1}$. Distal migration of the shunt has often been reported ${ }_{1,2},{ }_{3},{ }_{4},{ }_{11}$. The pressure gradient between the cranial and peritoneal cavities decides the direction of migration ${ }_{6}, 12$. The mechanism of shunt migration involves adhesion, necrosis, penetration, perforation, migration and extrusion ${ }_{6,8}, 13$.

Two principal causes have been suggested to explain the shunt migration into the cranium: the mechanic force 
moving the shunt catheter into the cranium and the low resistance ${ }_{6}, 13$. In childhood, vigorous flexion-extension movements of head may act as a windlass, facilitating upward migration of the shunt catheter ${ }_{10}$. Over and above that, the distance between the ventricular and the peritoneal ends of the catheter is smaller than in adults, and proximal migration is easier $_{13}$.

Shimizu et al ${ }_{13}$ reported a case with visual shortage and seizures. Those authors suggested that the cause of migration shunt catheter had been related to stress due to seizures, constipation and osteolysis insulted by craniotomy. Gupta \& Mann ${ }_{8}$ reported a case of shunt migration in a child with Dandy Walker cyst. Absence of raised intracranial pressure in this case suggests equilibration of cerebrospinal fluid pressure gradient. The diagnosis was incidental and the patient can be followed up expectantly. Cerrón-Rojas et al 5 reported a case of simultaneous cephalic migration into the intraventricular and subdural spaces. Those authors concluded that some factors are necessary: such as detachment of the shunt of the distal end (technical fault), underlying disease (porencephaly), dynamic factors causing expulsion (abdominal peristaltic movements), dynamic translocation factor (neck movements), dynamic attraction factor (increased cerebrospinal fluid reabsorption) and unishunt catheter (offering no resistance to passage through the trepanation orifice) ${ }_{5}$. Technical fault is reported such a cause of migration by others authors ${ }_{6,8}$.

The treatment consists of removing the migrated shunt and implantation of a new shunt, preferably with a reservoir ${ }_{1,9}$. Migration of shunt is not prevented by locks and slip clips 7,8

\section{CORRESPONDENCE TO}

Dr. Carlos Umberto Pereira, M.D. Augusto Maynard Avenue, 245/404 49015-380 Aracaju - Sergipe, Brazil Tel: $55+79+2130518$ e-mail: umberto@infonet.com.br

\section{References}

1. Acharya R, Bhutani A, Saxena H, Madan VS. Complete migration of ventriculoperitoneal shunt into the ventricle. Neurol Sci. 2002; 23:75-77.

2. Albala DM, Danaher JW, Huntsman WT.

Ventriculoperitoneal shunt migration into the scrotum. Am Surg 1989; 55:685-688.

3. Aoki N. Lumboperitoneal shunt: clinical applications, complications and comparison with ventriculoperitoneal shunt. Neurosurgery 1990; 26:998-1004.

4. Besson R, Hladky JP, Dhellemmes P, Debeugny P. Peritoneal pseudocyst-ventriculo-peritoneal shunt complications. Eur Pediatr Surg 1995; 5:195-197. 5. Cerrón-Rojas VR, Vega-Basulto S, Varela-Hernández A, Montejo-Montejo J, Gutiérrez-Muñoz FG. Simultaneous Cephalic Migration of a ventriculoperitoneal shunt into the intraventricular and subdural spaces. Rev Neurol 2001; 33:437-439.

6. Choudhury AR. Avoidable factors that contribute to the complications of ventriculoperitoneal shunt in childhood hydrocephalus. Child's Nerv Syst 1990; 6:346-349.

7. Gaskill SJ, Marlin AE. Pseudocysts of the abdomen associated with ventriculoperitoneal shunts: a report of twelve cases and a review of the literature. Pediatr Neurosci $1989 ; 15: 23-26$

8. Gupta PK, Dev EJ, Lad SD. Total migration of a ventriculoperitoneal shunt into the ventricles. $\mathrm{Br} \mathrm{J}$

Neurosurg. 1999; 13:73-74.

9. Gupta PK, Mann KS. Shunt migration into a Dandy Walker cyst. Neurol India. 2000 48:89-90.

10. Kanai M, Kawano K, Uehara S. Upward migration of the L-P shunt catheter into the cranial base. Osaka City Med J. 1999; 45:123-127.

11. Pereira CU, Silva AD, Barreto AS, Duarte GC, Braz PC. Peritoneal catheter extrusion through the scrotal sac. Case report. Rev Chil Neurocirug 2002; 70-71.

12. Serlo W, Fernell E, Heikkinen E, Anderson H, Von Wendt L. Functions and complications of shunt in different etiologies of childhood hydrocephalus. Child's Nerv Syst 1990; 6:92-94.

13. Shimizu S, Machizuki T, Nakayama K, Fujii K. Visual field defects due to valve migration into the cranium. Acta Neurochir (Wien) 2002; 144:1055-1056 


\section{Author Information}

Carlos Umberto Pereira, M.D., PhD

Department of Neurosurgery, Federal University of Sergipe

Egmond Alves Silva Santos, M.D.

Department of Neurosurgery, Federal University of Sergipe 